\title{
B-type natriuretic peptide-guided therapy for heart failure (HF): a systematic review and meta-analysis of individual participant data (IPD) and aggregate data
}

Maria Pufulete ${ }^{1 *}$ D, Rachel Maishman ${ }^{1}$, Lucy Dabner ${ }^{1}$, Julian P. T. Higgins², Chris A. Rogers ${ }^{1}$, Mark Dayer $^{3}$, John MacLeod ${ }^{2}$, Sarah Purdy², William Hollingworth², Morten Schou ${ }^{4}$, Manuel Anguita-Sanchez ${ }^{5}$, Patric Karlström Michael Kleiner Shochat ${ }^{7}$, Theresa McDonagh ${ }^{8}$, Angus K. Nightingale ${ }^{9}$ and Barnaby C. Reeves ${ }^{1}$

\begin{abstract}
Background: We estimated the effectiveness of serial B-type natriuretic peptide (BNP) blood testing to guide up-titration of medication compared with symptom-guided up-titration of medication in patients with heart failure (HF).

Methods: Systematic review and meta-analysis of randomised controlled trials (RCTs). We searched: MEDLINE (Ovid) 1950 to 9/06/2016; Embase (Ovid), 1980 to 2016 week 23; the Cochrane Library; ISI Web of Science (Citations Index and Conference Proceedings). The primary outcome was all-cause mortality; secondary outcomes were death related to HF, cardiovascular death, all-cause hospital admission, hospital admission for $H F$, adverse events, and quality of life. IPD were sought from all RCTs identified. Random-effects meta-analyses (two-stage) were used to estimate hazard ratios (HR) and confidence intervals (Cls) across RCTs, including HR estimates from published reports of studies that did not provide IPD. We estimated treatment-by-covariate interactions for age, gender, New York Heart Association (NYHA) class, HF type; diabetes status and baseline BNP subgroups. Dichotomous outcomes were analysed using random-effects odds ratio (OR) with 95\% Cl.

Results: We identified 14 eligible RCTs, five providing IPD. BNP-guided therapy reduced the hazard of hospital admission for HF by $19 \%$ ( $13 \mathrm{RCTs}$, HR $0.81,95 \% \mathrm{Cl} 0.68$ to 0.98 ) but not all-cause mortality (13 RCTs; HR 0.87 , $95 \% \mathrm{Cl} 0.75$ to 1.01 ) or cardiovascular mortality (5 RCTs; OR $0.88,95 \% \mathrm{Cl} 0.67$ to 1.16$)$. For all-cause mortality, there was a significant interaction between treatment strategy and age $(p=0.034,11 \mathrm{RCTs} ; \mathrm{HR} 0.70,95 \% \mathrm{Cl}$ $0.53-0.92$, patients $<75$ years old and $\mathrm{HR} 1.07,95 \% \mathrm{Cl} 0.84-1.37$, patients $\geq 75$ years old); ejection fraction $(p=0.026,11$ RCTs; HR $0.84,95 \% \mathrm{Cl} 0.71-0.99$, patients with heart failure with reduced ejection fraction (HFrEF); and HR 1.33, 95\% Cl 0.83-2.11, patients with heart failure with preserved ejection fraction (HFpEF)). Adverse events were significantly more frequent with BNP-guided therapy vs. symptom-guided therapy (5 RCTs; OR $1.29,95 \%$ Cl 1.04 to 1.60 ).
\end{abstract}

Conclusion: BNP-guided therapy did not reduce mortality but reduced HF hospitalisation. The overall quality of the evidence varied from low to very low. The relevance of these findings to unselected patients, particularly those managed by community generalists, are unclear.

Systematic review registration: PROSPERO CRD42013005335

Keywords: Heart failure, B-type natriuretic peptide, Systematic review, IPD meta-analysis

\footnotetext{
* Correspondence: maria.pufulete@bristol.ac.uk

${ }^{1}$ Clinical Trials and Evaluation Unit, School of Clinical Sciences, University of

Bristol, Level 7, Bristol Royal Infirmary, Queen's Building, Bristol BS2 8HW, UK

Full list of author information is available at the end of the article
}

(c) The Author(s). 2018 Open Access This article is distributed under the terms of the Creative Commons Attribution 4.0 International License (http://creativecommons.org/licenses/by/4.0/), which permits unrestricted use, distribution, and reproduction in any medium, provided you give appropriate credit to the original author(s) and the source, provide a link to the Creative Commons license, and indicate if changes were made. The Creative Commons Public Domain Dedication waiver (http://creativecommons.org/publicdomain/zero/1.0/) applies to the data made available in this article, unless otherwise stated. 


\section{Background}

Heart failure (HF) affects over 500,000 people in the UK. Despite advances in medical treatment and evidence-based guidelines, patients continue to have high morbidity and poor life expectancy [1]. Many patients are not treated according to guidelines and do not receive optimal doses of available medications [2]. Clinicians sometimes find it difficult to recognise the early stages of worsening HF and are reluctant to increase doses of medications because of concerns about side effects such as renal failure and hypotension. Recently, biomarkers such as natriuretic peptides (B-type natriuretic peptide, $\mathrm{BNP}$; or the $\mathrm{N}$-terminal part of the precursor peptide of $\mathrm{BNP}, \mathrm{N}$-terminal pro-B-type natriuretic peptide, NT-proBNP, collectively referred to here as BNP), have been used as a more objective means of assessing HF severity and to prompt more appropriate titration of HF therapies.

Several randomised controlled trials (RCTs) have assessed whether using serial BNP tests to guide up-titration of medication improves clinical outcomes compared with symptom-guided therapy. The RCTs were heterogeneous in design. Most used a BNP-lowering strategy, where a BNP target was set (a single target for all patients or an individualised target) and HF medications were intensified to lower or maintain $\mathrm{BNP}$ at the pre-specified target. A few used a BNP-monitoring strategy, where the treating clinician was allowed to intensify HF medications using serial BNP measurements but no BNP target was set. Data from RCTs using a BNP-lowering strategy have been pooled in six aggregate data meta-analyses [3-8], one individual participant data (IPD) meta-analysis [9] All of these analyses showed that patients in the BNP-lowering group had better outcomes.

We conducted a systematic review and meta-analysis of IPD and aggregate data including all RCTs, regardless of BNP-guiding strategy [10]. Specific objectives were to estimate the effect of BNP-guided therapy on clinical outcomes; to estimate the extent of effect modification for key outcomes in specific subgroups; and to quantify the extent to which improved outcomes are explained by up-titration of medication and/or reduction in BNP levels. In this paper, we present an update of our meta-analysis to include data from the Guide-IT RCT [11], the largest RCT to date (894 patients), which planned to recruit 1100 patients but was terminated early because of futility.

\section{Methods}

The protocol for the meta-analysis has been published previously [12]. The study population was all patients aged over $>18$ years who were being treated for HF in primary or secondary care BNP-guided therapy or symptom-guided therapy. The primary outcome was all-cause mortality; secondary outcomes were death related to HF, cardiovascular death, all-cause hospitalisation, HF hospitalisation, adverse events, and quality of life.

\section{Search methods for identification of studies}

The search strategy is shown in Additional file 1: Appendix 1. We searched the following electronic databases: MEDLINE (Ovid) 1950 to 6 September 2016; Embase (Ovid), 1980 to 2016, week 23; the Cochrane Library; ISI Web of Science (Citations Index and Conference Proceedings). We also searched the World Health Organization International Clinical Trials Registry Platform (WHO ICTRP; http://apps.who.int/trialsearch/) and Current Controlled Trials (http://www.isrctn.com/) to identify trials in progress. We reviewed reference lists of all full-text papers and also searched grey literature (http:// www.opengrey.eu/ and Google Scholar).

\section{Study selection}

Two review authors (MP and LD) independently triaged the titles and abstracts identified by the search and assessed the full text of all studies identified as relevant to the review. Differences in assessment by were resolved through discussion with a third author (RM). No language restriction was applied.

\section{Establishing the collaboration}

Corresponding authors of eligible RCTs were invited to join the collaboration and were sent the IPD meta-analysis protocol with a cover letter explaining the study.

\section{Quality assessment}

Two review authors (MP and LD) independently assessed the risk of bias (in accordance with recent Cochrane Collaboration guidelines [13]) in each included RCT. For blinding and incomplete outcome data, risk of bias was assessed separately for pre-specified outcome domains (all-cause mortality, cause-specific mortality, adverse events, and quality of life). For incomplete outcome data and selective outcome reporting, risk of bias was assessed only in RCTs that contributed aggregate data.

\section{Data collection and checking}

IPD were collated into a single database. All datasets were checked for consistency against the original publication reports and discrepancies were discussed and clarified with authors via email. Where authors did not provide clarification, we documented assumptions that were made regarding the data.

\section{Statistical analysis}

Meta-analysis was carried out if $>2$ RCTs reported data on the outcome of interest. All analyses were performed on an 
intention-to-treat basis. Hazard ratios (HR) were estimated using Cox regression modelling for each RCT. For RCTs that did not provide IPD, HR estimates from published reports [14] were combined with HR estimates derived from the IPD. The HRs were combined across RCTs using random-effects meta-analysis (two stage model results using the generic inverse-variance method) [15], and consistency of findings across studies was assessed using the $I^{2}$ test statistic. Fixed-effects meta-analysis was also performed as a secondary analysis. Subgroup effects were determined by estimating treatment-by-covariate interaction terms for each RCT and combining the HRs across RCTs as for the main effects [16]. Covariates defining subgroups were age $(<75$ vs. $\geq 75$ years); gender; New York Heart Association (NYHA) class (class I/II vs class III/IV); type of HF (reduced ejection fraction, HFrEF, vs. preserved ejection fraction, HFpEF, based on LVEF, $<40 \%$ in studies providing IPD and $<45 \%$ in studies providing aggregate data); diabetes status, BNP level ( $\leq$ vs. $>$ median at baseline across all RCT participants, with separate medians calculated for RCTs that reported BNP and NTpro-BNP; cause of HF (ischaemic/ non-ischaemic); previous atrial fibrillation; body mass index; systolic blood pressure. The age cut-off was chosen for consistency with other studies in elderly HF populations and to allow easy comparison with the meta-analysis by Troughton et al. [9]. For the LVEF cut-off, we used the lower limit of normal LVEF (40\%) used in clinical practice. This threshold of $40 \%$ was pre-specified by the study authors, although for the aggregate data studies, we had to use the cut-off of $45 \%$ specified by the researchers of the existing IPD meta-analysis [17]. As for the main analysis, HR estimates from published reports [14] were combined with HR estimates derived from the IPD. We calculated interactions when these were not reported from subgroup-specific HRs with 95\% confidence intervals (CI) from studies using aggregate data and pooled them with interactions from additional RCTs which had contributed IPD for this study. For cardiovascular mortality and adverse events, we calculated odds ratios (OR) and 95\% CI in each trial and pooled these across RCTs using random effects meta-analyses. We assessed the certainty of the evidence across each outcome measure using the GRADE approach (risk of bias, consistency of effect, imprecision, indirectness, and publication bias) (http://www.gradeworkinggroup.org/.).

The relationship between the size of the treatment effect and the change in BNP values was investigated by plotting the ratio of change in BNP values (calculated using the formula below) against the hazard rate for each study with data available.
For the three studies providing IPD data, the ratio of change was also calculated using the patient-specific change from baseline; after logarithmic transformation of all BNP values, the median change from baseline was calculated in each treatment group, and the ratio of the exponents of medians was calculated. All but two aggregate data studies provided median BNP values in their published report. For the two that did not (Christchurch Pilot and Signal-HF), we used the summary statistic reported (see Table 3). All analyses were conducted using Stata, v14.0, using the 'ipdmetan' command [18].

\section{Sensitivity analysis}

The following sensitivity analyses were conducted: restricting the analysis to RCTs that defined a BNP target; and restricting the analysis to RCTs with good allocation concealment, since this has been shown to be an important source of bias in RCT.

\section{Checking for publication and data availability bias}

Funnel plots were used to investigate association between the precision of the effect size and effect size (which could be due to publication bias or 'small study effects') [19], including and excluding RCTs for which IPD were unavailable. We included funnel plots only if a sufficient number of studies (more than 10) were available for each outcome.

\section{Results}

Figure 1 shows the flow of studies through the review process. Full-text screening of 70 articles and unpublished studies identified 19 studies eligible for inclusion for which IPD were requested. Of these, 14 studies were included in the meta-analysis (5 IPD and 9 aggregate).

Table 1 shows the characteristics of the included RCTs. Of the 14 RCTs included in the meta-analysis, eight were conducted in Europe [20-27], two in New Zealand [28, 29], three in North America [11, 30, 31], and one in Israel [32]. One RCT (Time-CHF) published results separately for HFrEF [26] and HFpEF [33]. Only one RCT [25] (Signal-HF, Sweden) was conducted in primary care; the other 13 were conducted in hospital HF clinics, with most of these recruiting patients during or immediately after hospitalisation for HF. Twelve RCTs used a BNP-lowering strategy [11, 20-26, 28-31] and two used a BNP-monitoring strategy [27, 32]. Of the 12 RCTs that used a BNP-lowering strategy, nine set a single target (BNP 100-300 pg/ml; NT-proBNP 400-2200 pg/ml 


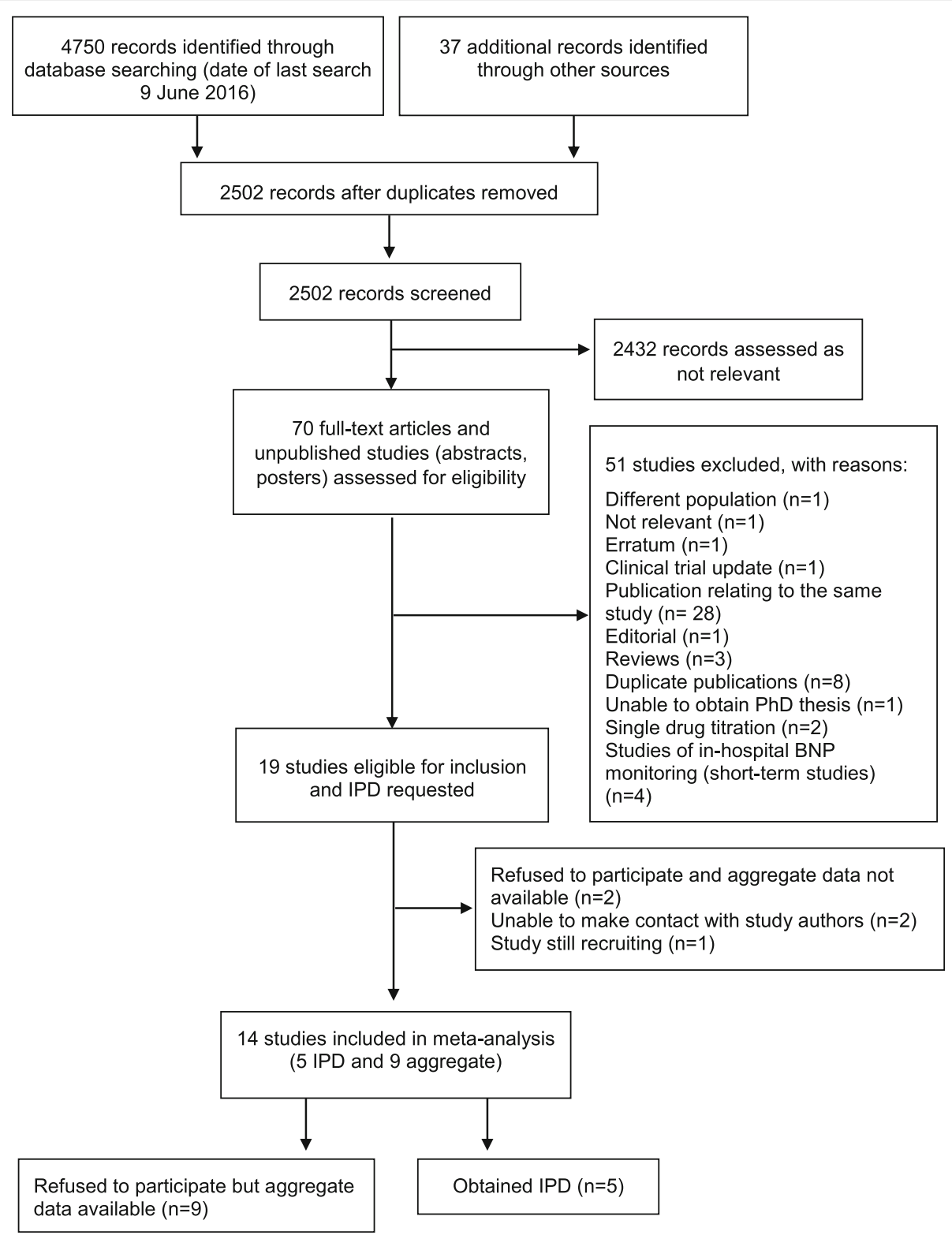

Fig. 1 PRISMA flow diagram

$[11,20,21,23,24,26,28-30])$, two of which used age-stratified $(<75$ years and $\geq 75$ years $[24,26])$ targets, and three set an individual BNP target (BNP level at discharge, reduction of $50 \%$ from baseline [22, 25, 31]). Algorithms for modifying treatment in the BNP-guided therapy groups differed slightly between RCTs, but all were based on stepwise titration of therapy according to clinical guidelines. Treatment for symptom-guided therapy groups used an algorithm designed to achieve a target HF score based on signs and symptoms (e.g. Framingham HF score and NYHA class) in five RCTs $[20,26,28,29,31]$ and was entirely at the clinician's discretion in seven RCTs [11, 21-25, 30].
In the IPD dataset, the mean age of participants was 70 years, three quarters of patients were men, most patients had LV systolic dysfunction (median LVEF, 30\%) and over $80 \%$ ) had NYHA class II or III (Table 2). The patients in RCTs providing aggregate data had similar characteristics (Table 3).

Eleven out of the 14 included RCTs (79\%) were rated as having a high risk of bias across at least one risk domain (Additional file 2: Appendix 2). The main factor that contributed to ratings of high risk of bias was the lack of blinding (of participants and care-giving clinicians). None of the funnel plots generated for the 


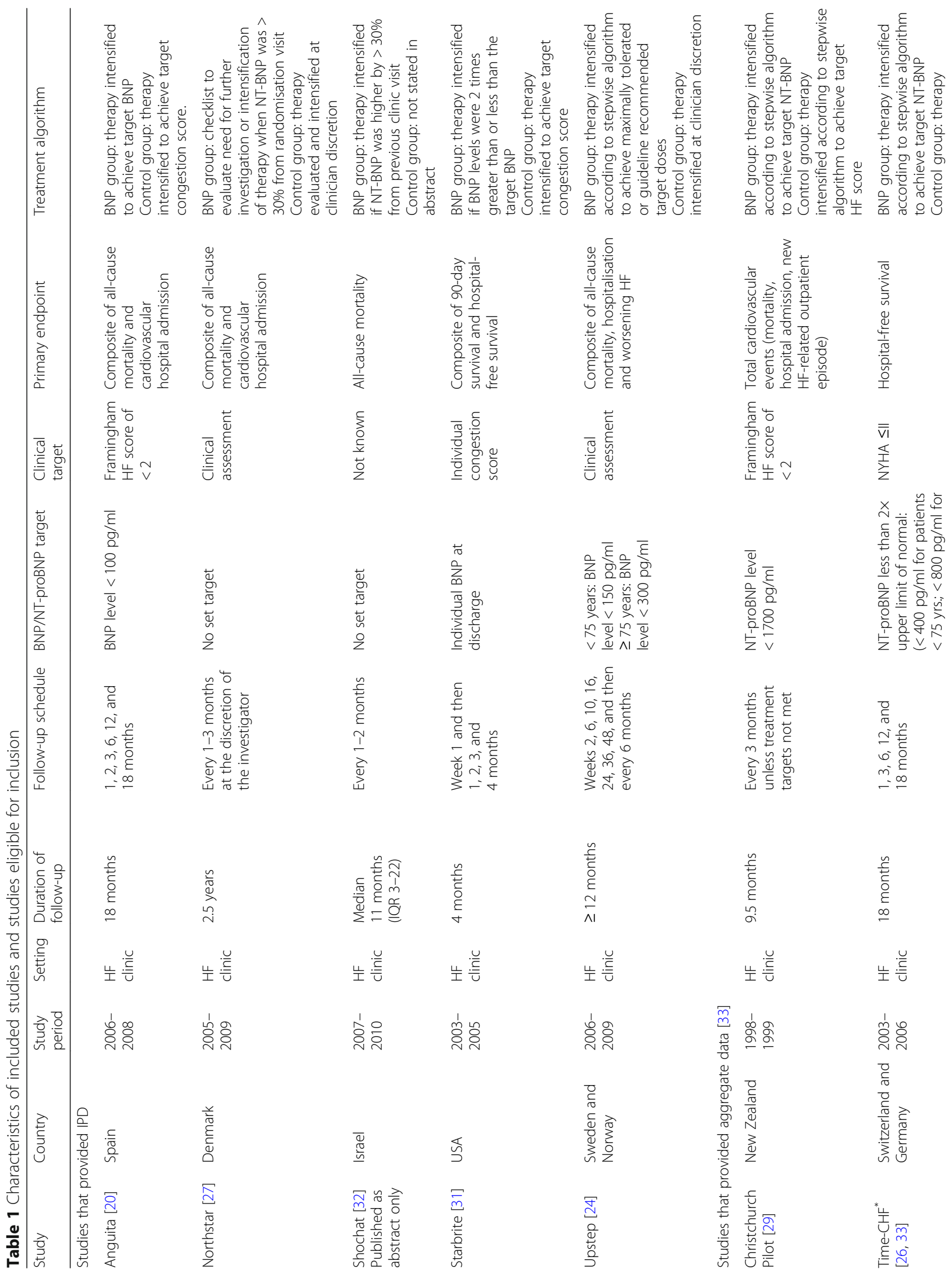




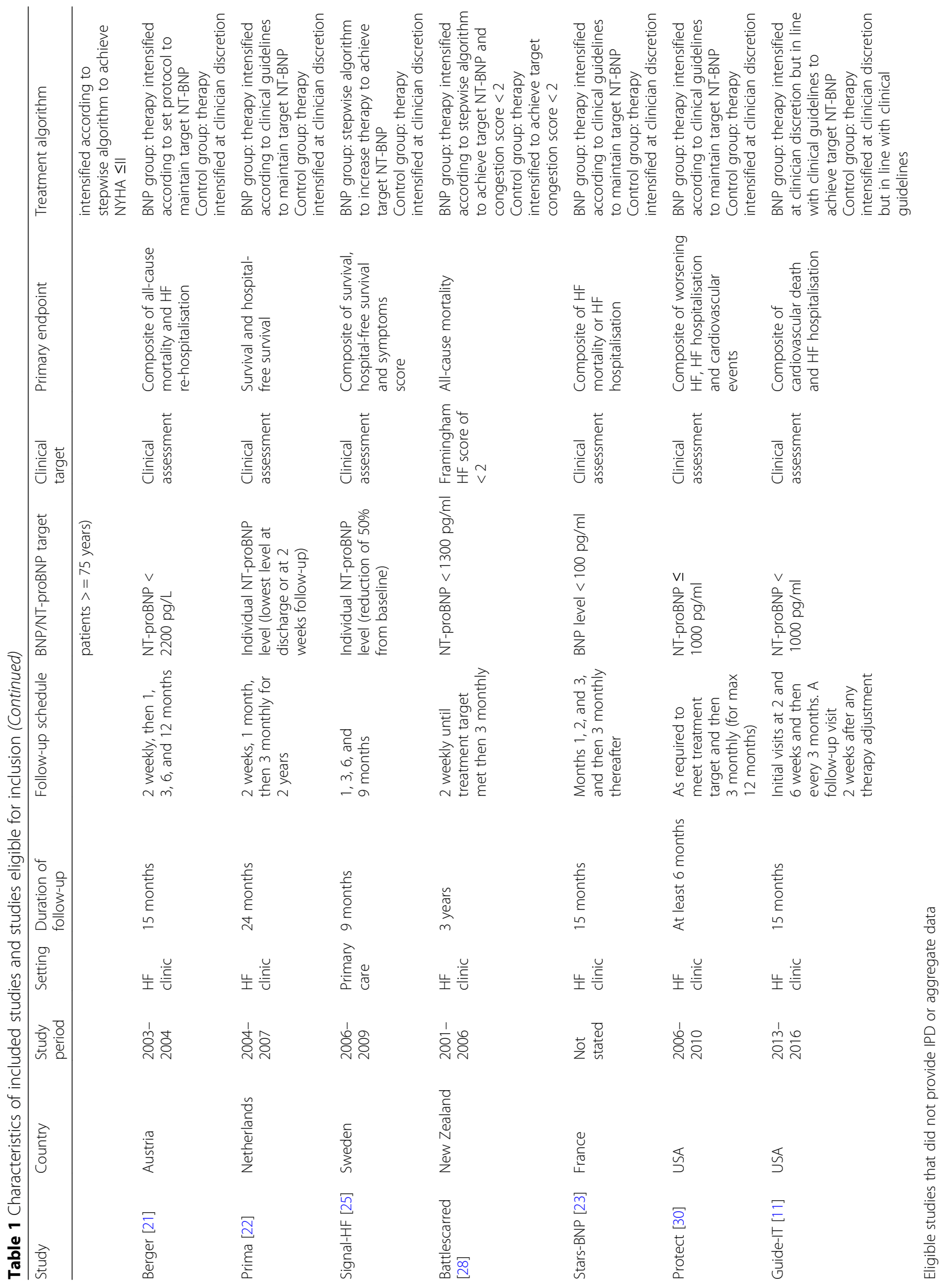




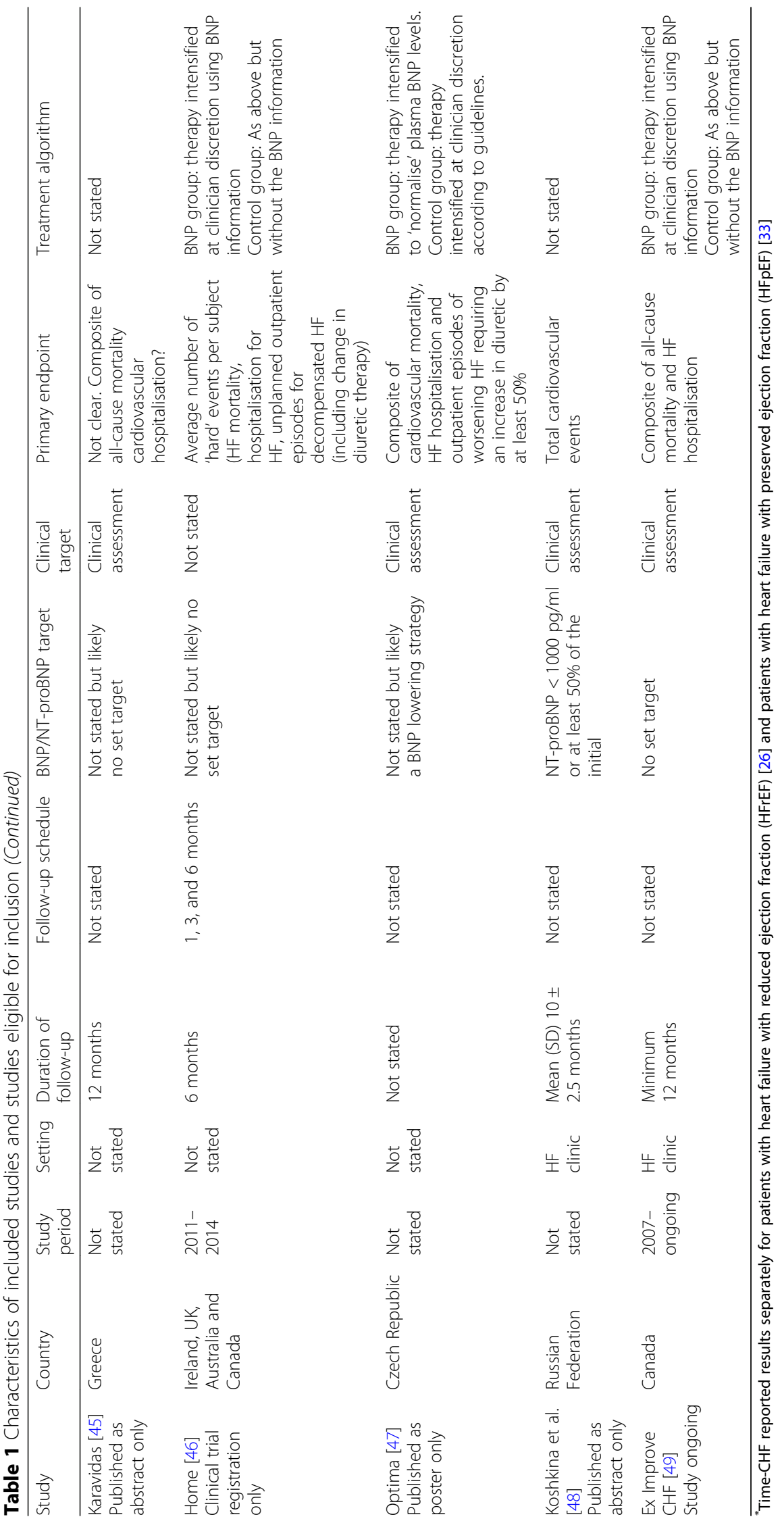




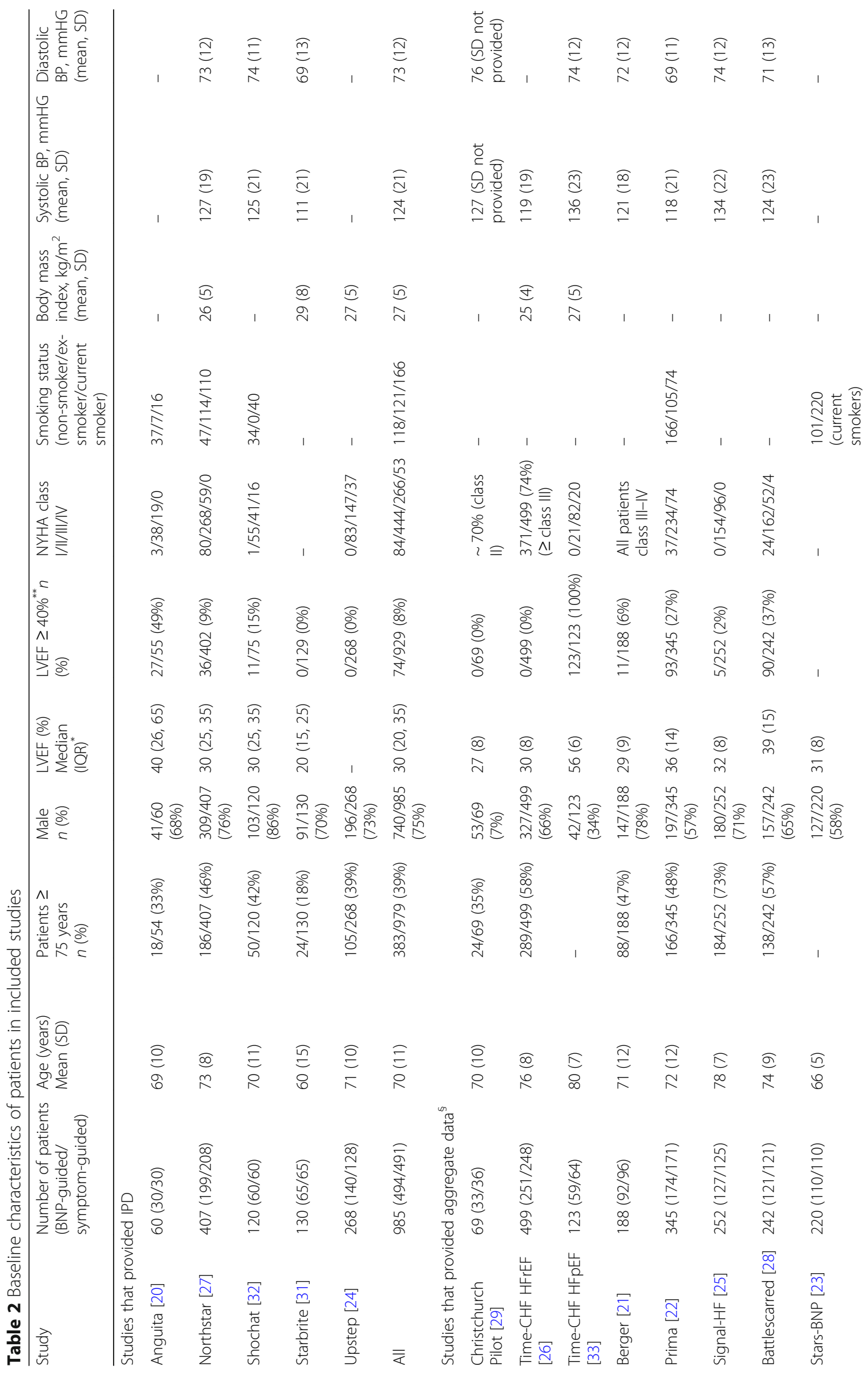




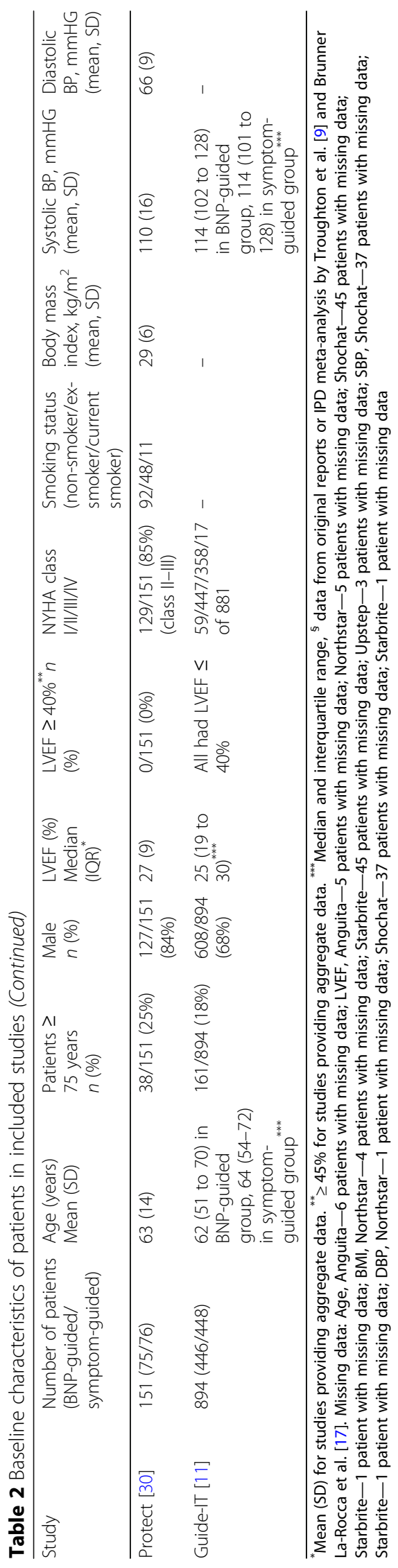




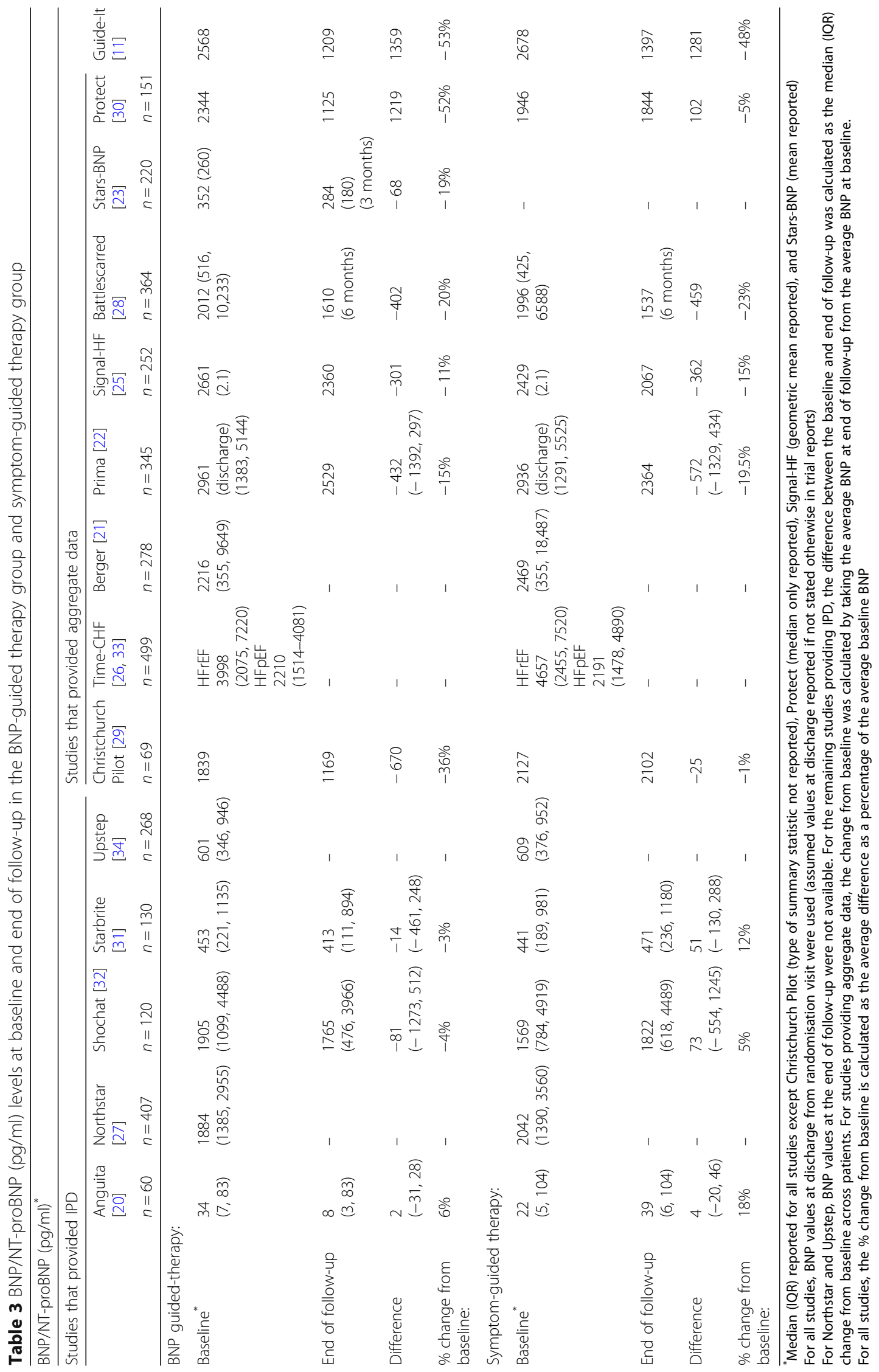


outcomes with more than 10 studies contributing data suggested marked asymmetry (Additional file 3: Appendix 3). There were no significant issues identified with the IPD datasets provided. The overall quality of the body of evidence for all outcomes varied from low to very low (Table 4).

\section{Primary outcome}

Across 13 RCTs that reported all-cause mortality, 17\% (320/1845) of patients in the BNP-guided therapy group, and $20 \%(367 / 1846)$ of patients in the symptom-guided therapy group died during follow up. Median follow-up in the five RCTs that provided IPD was 18 months (IQR 8-27). BNP-guided therapy did not reduce the hazard of death from any cause compared with symptom-guided therapy (HR 0.87, 95\% CI 0.75 to 1.01) (Fig. 2). There was no significant heterogeneity between RCTs. The sensitivity analysis excluding the two RCTs that did not use a BNP-lowering strategy did not alter this finding (HR $0.86,95 \% \mathrm{CI} 0.73$ to 1.01$)$. The sensitivity analysis combining the effect estimates from three RCTs that were judged to have had good allocation concealment showed no difference in the hazard of death between groups (HR 0.93, 95\% CI 0.60-1.44).

\section{Secondary outcomes}

Five RCTs provided aggregate data on numbers of patients with cardiovascular death; these showed that $12 \%(120 / 963)$ of patients in the BNP-guided therapy group and $14 \%(130 / 946)$ of patients in the symptom-guided therapy group died because of a cardiovascular cause. BNP-guided therapy did not reduce the odds of cardiovascular death (OR 0.88, 95\% CI 0.66-1.16) (Fig. 3). Only two studies provided aggregate data on death due to HF; Stars-BNP [23] and Upstep [24] showed that 3\% (3/110) and $15 \%(21 / 140)$, respectively, of patients in the BNP-guided therapy group, and $8 \%(9 / 110)$ and $12.5 \%$ (16/128), respectively, of patients in the symptom-guided therapy group had a death directly attributable to HF.

Across six RCTs with data on all-cause hospitalisation, 58\% (285/493) of patients in the BNP-guided therapy group had at least one hospital admission, compared with 57\% (281/491) of patients in the symptom-guided therapy group. BNP-guided therapy did not reduce the hazard of all-cause hospitalisation (HR 0.97, 95\% CI 0.85-1.10) (Fig. 4). The results did not differ in the analysis restricted to RCTs that used a BNP-lowering strategy (HR 0.95, 95\% CI 0.81-1.11).

Across eight RCTs that provided data on numbers of patients with HF hospitalisation, there were 392/1328 patients $(29.5 \%)$ who had at least one hospitalisation for HF in the BNP-guided therapy group, compared with $452 / 1327$ patients $(34 \%)$ in the symptom-guided therapy group. BNP-guided therapy led to a lower hazard of hospitalisation due to HF (HR 0.81, 95\% CI 0.68-0.98) (Fig. 5). The results did not differ in the sensitivity analysis restricted to RCTs that set a BNP target (HR 0.77, 95\% CI 0.64-0.99). The sensitivity analysis with respect to allocation concealment was not performed because only two RCTs were classified as having a low risk of bias. In all meta-analyses (for primary and secondary outcomes), the results from the fixed-effects meta-analyses did not differ from the random-effects meta-analyses results.

\section{Subgroup analyses}

Stratum-specific treatment effects are reported in Additional file 4: Appendix 4. For all-cause mortality, there was a significant interaction between treatment strategy and age $(p=0.034,11 \mathrm{RCTs})$, and treatment strategy and LVEF ( $p=0.026,10 \mathrm{RCTs})$. BNP-guided therapy was beneficial for trial participants $<75$ years old (HR 0.70, 95\% CI 0.53-0.92) but not for trial participants $\geq 75$ years old (HR 1.07, 95\% CI 0.84-1.37). Similarly, BNP-guided therapy was beneficial for trial participants with HFrEF (HR 0.84, 95\% CI 0.71-0.99), but not those with HFpEF (HR 1.33, 95\% CI 0.832.11). This effect was largely driven by one RCT (Time-CHF); excluding this from the analysis attenuated the protective effect in the lower LVEF subgroup was attenuated (HR 0.89, 95\% CI 0.73-1.06).

There were no significant interactions between treatment strategy and any of the other covariates investigated in the subgroup analyses for any of the outcomes $(p>0.05)$. However, for age and LVEF, stratum-specific estimates for the secondary outcomes (all-cause and HF hospitalisations) were consistent with those for all-cause mortality, suggesting a protective effect of BNP-guided therapy.

\section{Changes in BNP from baseline to end of follow-up}

BNP levels at baseline and end of follow-up were available for nine RCTs (Table 3). In six of these [11, 22, 25, 28-30], BNP levels decreased in both the BNP-guided therapy group and the symptom-guided therapy group. There was no consistent relationship between the change in BNP from baseline between groups and the HR for all-cause mortality (Fig. 6). RCTs that provided evidence for a relationship (i.e. studies with the most extreme HRs for mortality favouring BNP guided-therapy and in which BNP fell substantially more in the BNP-guided group than in the symptom-guided group) provided least weight in the meta-analysis. Calculating the relative change between groups using IPD (for studies that provided IPD) provided even less evidence for a relationship. 


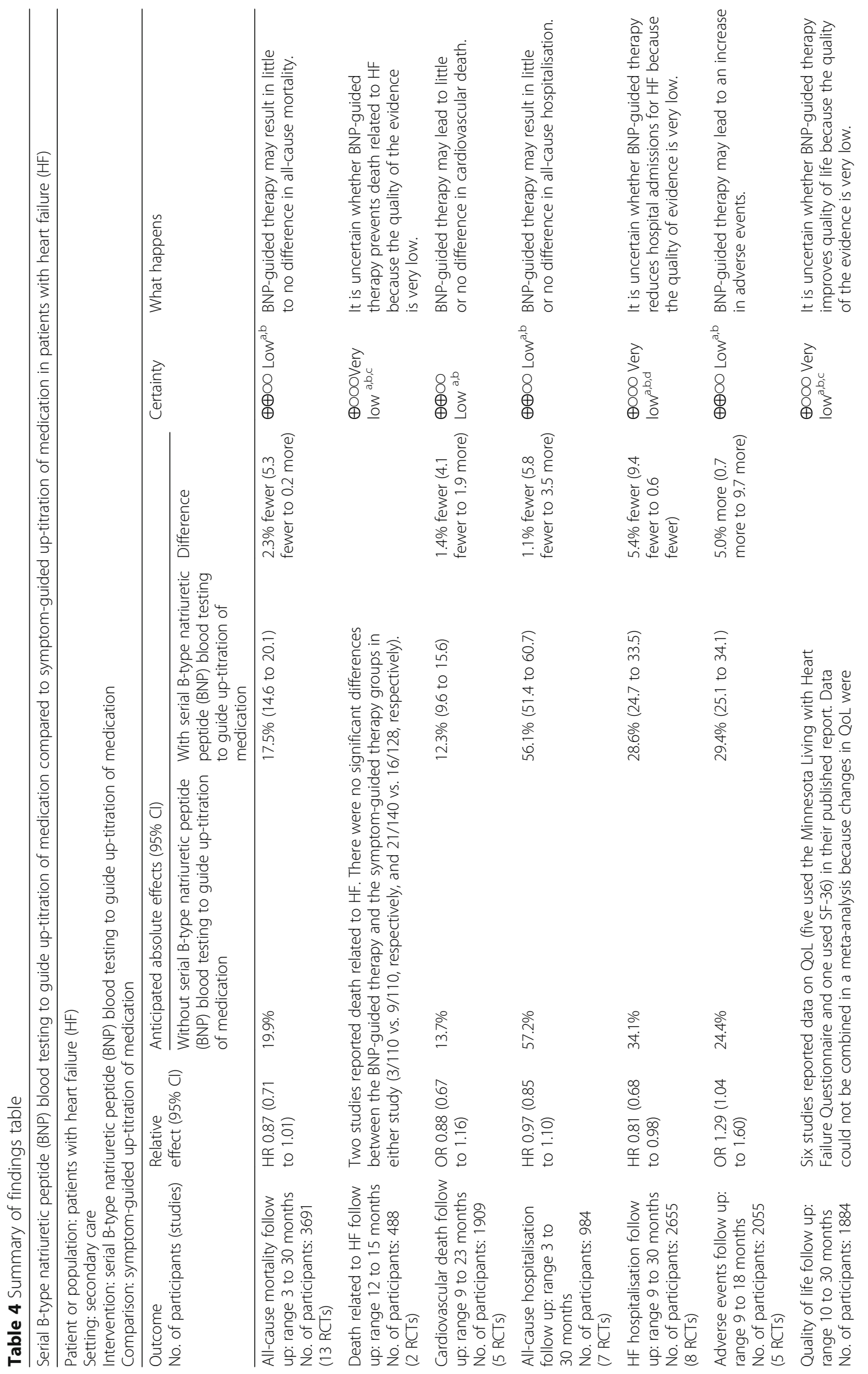




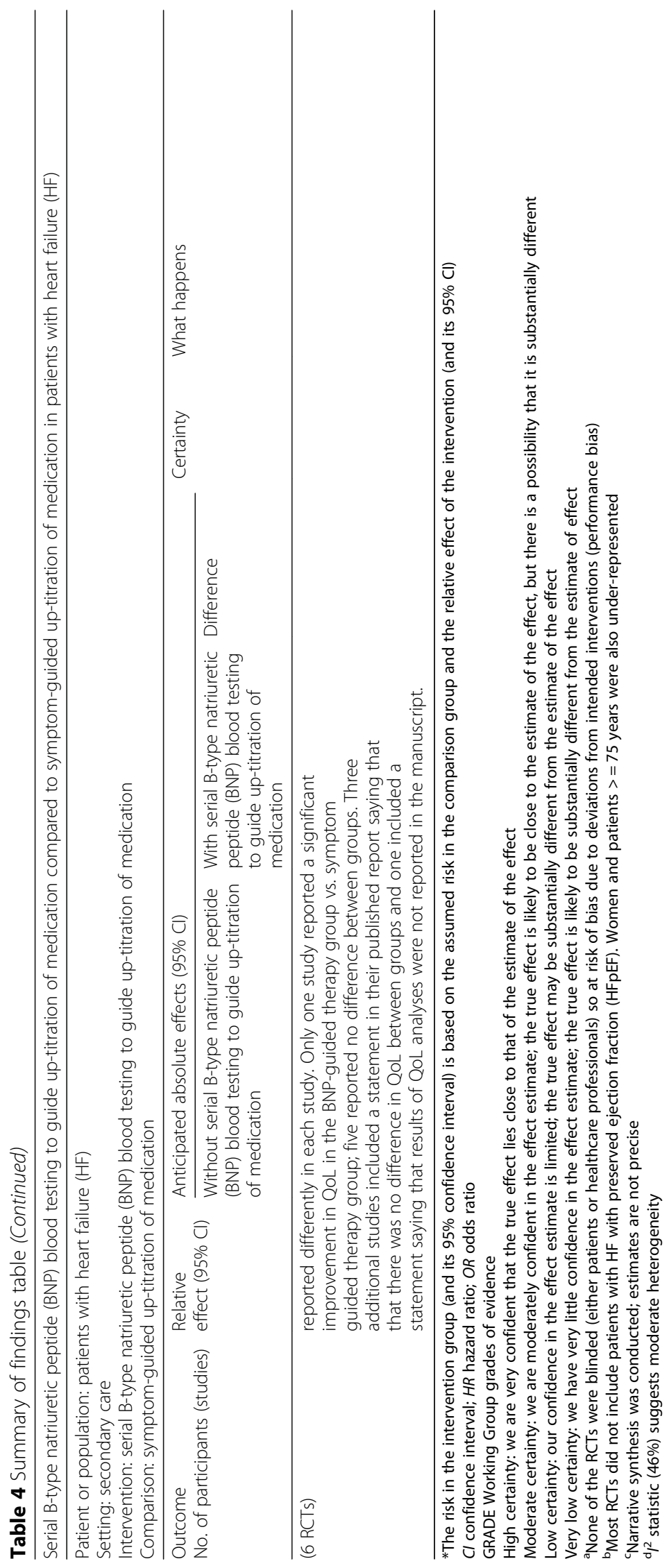




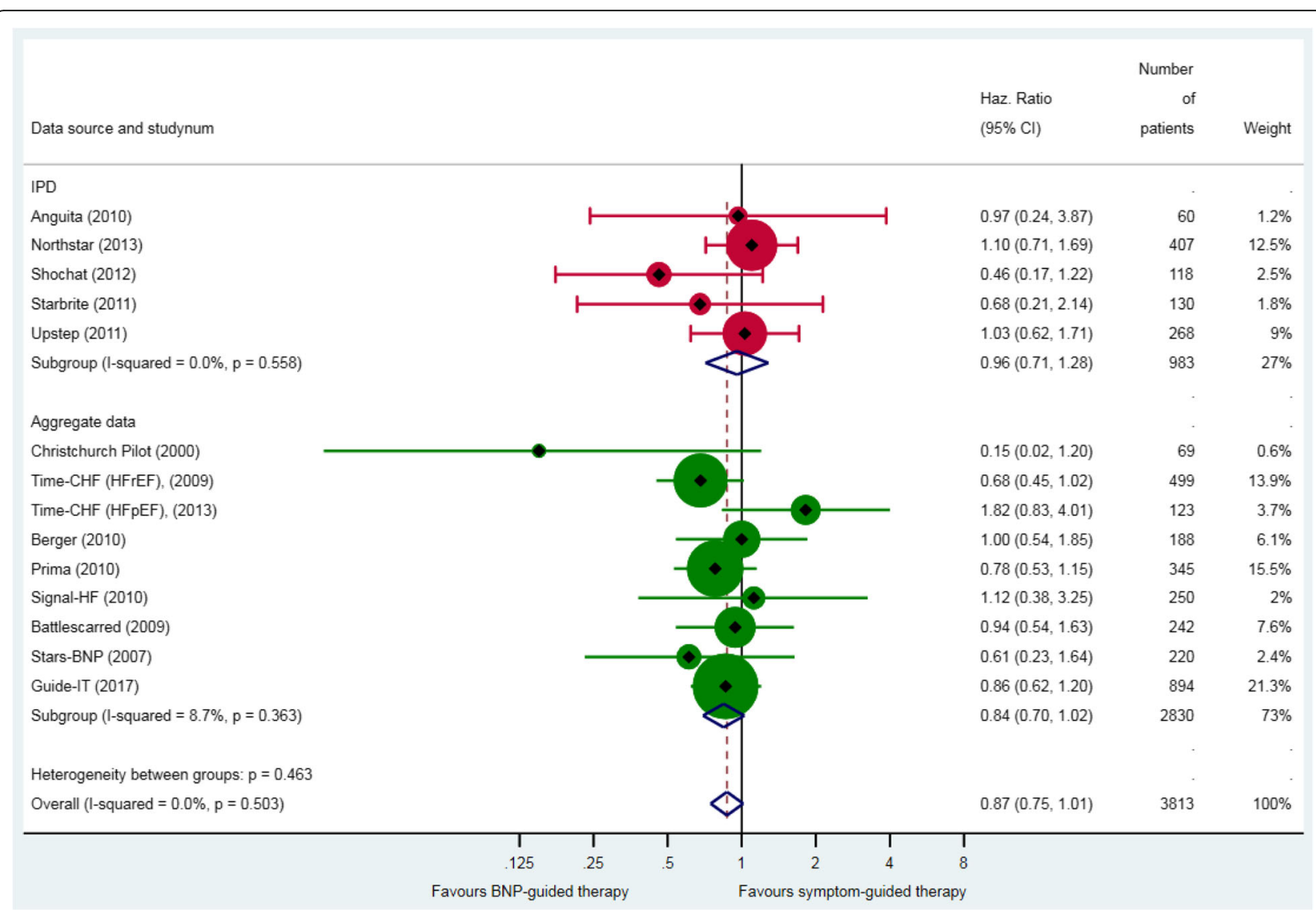

Fig. 2 All-cause mortality. Unadjusted individual hazards ratios (HR) with 95\% confidence intervals (CI) presented within IPD, aggregate data, and overall. Time-CHF reported results separately for patients with heart failure with reduced ejection fraction (HFrEF) [26] and patients with heart failure with preserved ejection fraction (HFpEF) [33]. HR for all-cause mortality was not available for the Protect study [30]. The $\mathrm{HR}$ and $95 \% \mathrm{Cl}$ from Guide-It [11] was adjusted for age, sex, left ventricular ejection fraction, NT-proBNP, and the presence of diabetes mellitus. Note: weights are from random effect analysis

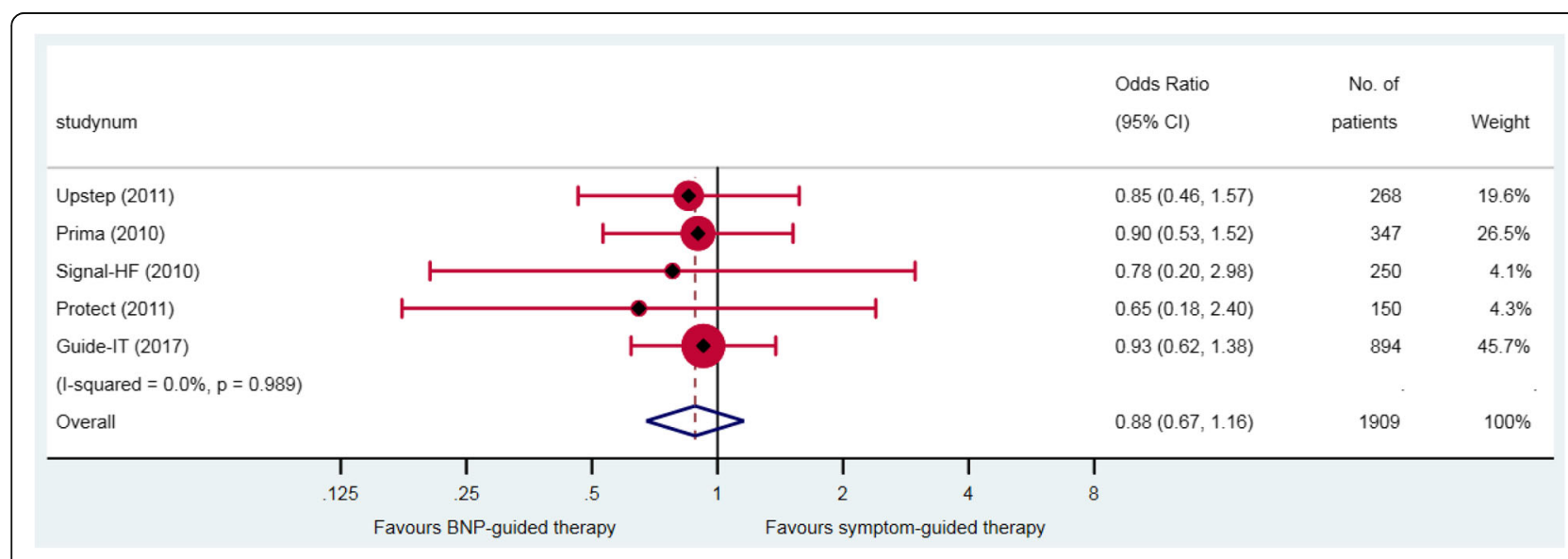

Fig. 3 Cardiovascular mortality. Odds ratio (OR) with 95\% confidence intervals (Cl) for five aggregate data studies. Note: weights are from random effect analysis 


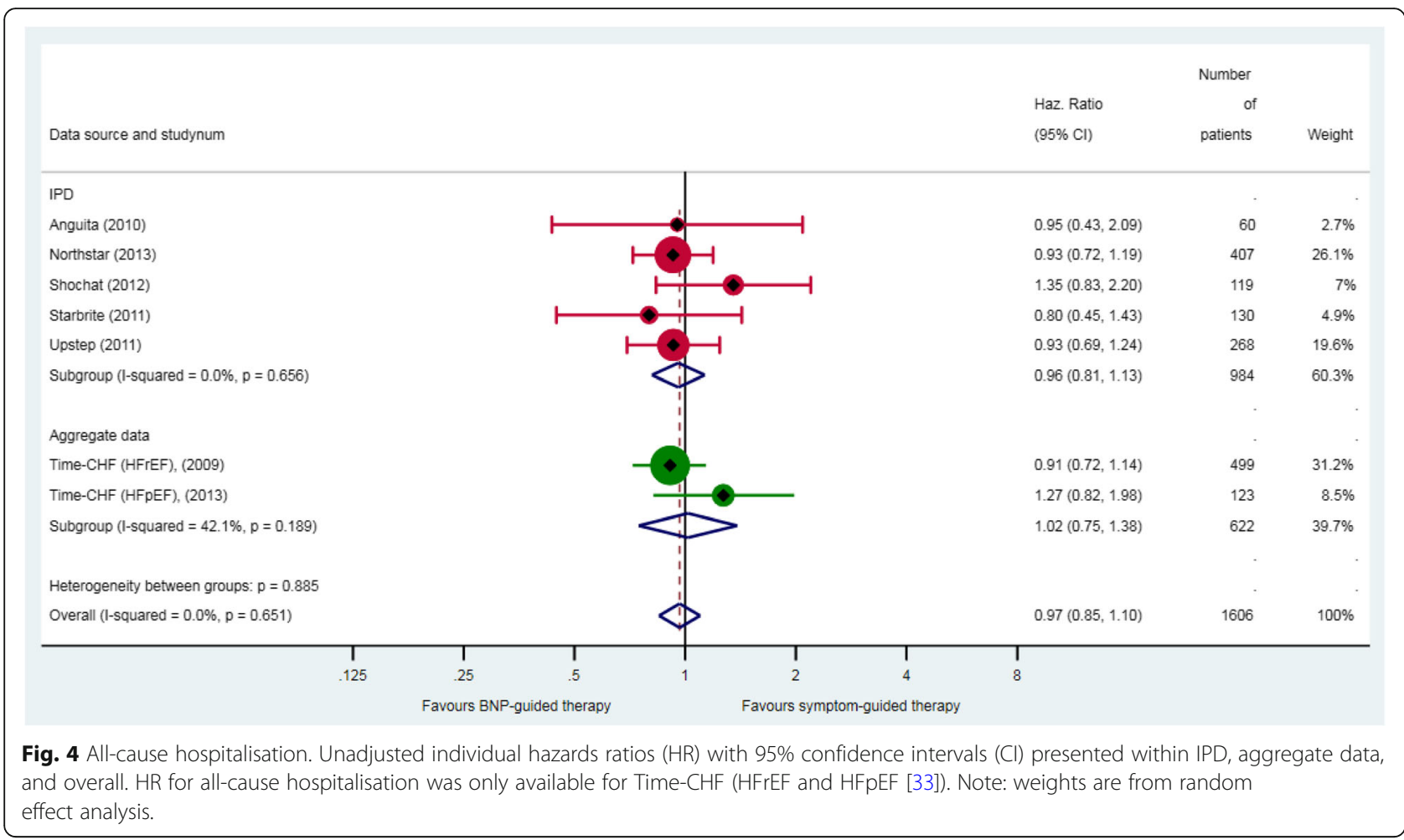

\section{Medication changes}

We could not combine IPD and aggregate data to investigate the association between changes in medication and outcomes because changes in medication were inconsistently reported in studies on both IPD studies and aggregate data studies.

\section{Adverse events and discontinuation}

None of the IPD studies provided data on adverse events. Five aggregate data studies $[11,25,26,29,30,33]$ provided data on total number of adverse events by group; these showed that 29\% (293/1023) of patients in the BNP-guided therapy group and 14\% (130/946) of patients in the symptom-guided therapy group experienced an adverse event. Adverse events were significantly more frequent in the BNP-guided therapy group compared with that in symptom-guided therapy group (OR 1.29, 95\% CI 1.04 to 1.60) (Fig. 7). Adverse events most commonly reported included renal impairment and hypotension, one study reported additional adverse events such as hyper/hypokalaemia, anaemia, fever, dizziness, gastrointestinal bleeding, respiratory infection, and syncope.

\section{Quality of life (QoL)}

None of the IPD studies provided QoL data both at baseline and follow-up. QoL data were available from aggregate data in six studies (including the published reports of two IPD studies: Northstar [27] and Upstep [24]). These could not be pooled in a meta-analysis because changes in
QoL were reported differently in each study. Five studies assessed QoL using the Minnesota Living with Heart Failure questionnaire [22, 26-28, 30], and one study [24] assessed QoL using the SF-36 questionnaire. Northstar [27] reported no change in QoL in either group [median (IQR) change 0 ( -6 to 2$)$ and 0 ( -5 to 6$)$ between baseline and end of study visit (6 months to 4.5 years), in the BNP-guided therapy group and symptom-guided therapy group, respectively]. Three of the aggregate data studies showed that QoL improved significantly and similarly in both groups: Battlescarred [28]: mean (SD) 36.5 (22.7) and 36.6 (23.1) at baseline vs. 28.8 (21.6) and 26.5 (22.0) at 12 months in the BNP-guided therapy group and symptom-guided therapy group, respectively; Prima [22] (median (IQR), 47 (34 to 62) and 48 (36 to 60) at baseline vs. 20 (3-36) and 23 (10-38) at 12 months follow up, in the BNP-guided therapy group and symptom-guided therapy group, respectively; Time-CHF [26] (mean (SD), 38.3 (20.2) and 40.2 (20.3) at baseline vs. 27.7 (17.90 and 27.0 (18.6) at 12 months, in the BNP-guided therapy group and symptom-guided therapy group, respectively. Only one of the aggregate data studies showed a greater improvement in the BNP-guided therapy group compared with the symptom-guided therapy group [Protect [30] (median improvement between baseline and follow-up at 12 months, -10.0 vs. $-5.0, p=0.05$, in the BNP-guided therapy group and symptom-guided therapy group, respectively]. The Upstep study [24] assessed quality of life using the SF-36 questionnaire (eight domains) and found no significant 


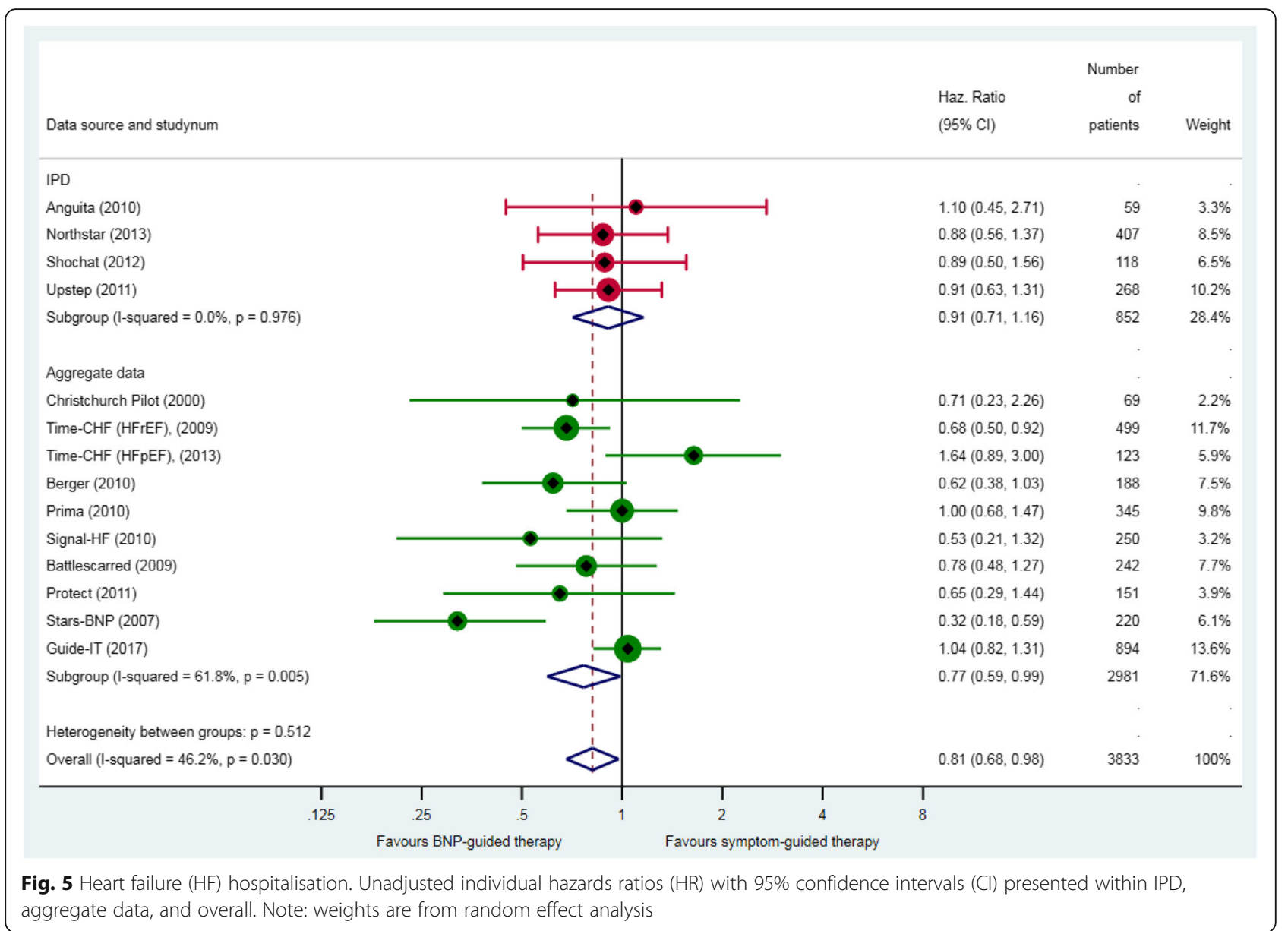

differences between groups [34]. The remaining studies did not provide data on QoL; three studies included a statement to say that the change/improvement in QoL was similar in both groups $[20,25,29]$, one study did not mention quality of life [31], while the Guide-It study included a statement saying that the results of QoL analyses were not reported in their manuscript [11].

\section{Discussion}

\section{Main findings}

Our meta-analysis, including data for up to 3968 patients with HF (1982 randomised to BNP-guided therapy and 1986 randomised to symptom-guided therapy) suggests that BNP-guided therapy may result in little to no difference in all-cause or cardiovascular mortality. It is uncertain whether BNP-guided therapy reduces hospital admissions for HF because the quality of evidence is very low. BNP-guided therapy may lead to an increase in adverse events. A previous IPD meta-analysis by Troughton et al. [9] (which excluded the subgroup of participants with HFpEF from the Time-CHF RCT) showed a $18 \%$ reduction in the hazard of death from any cause (HR 0.82, 95\% CI 0.67-1.00) and a $26 \%$ reduction in the hazard of hospital admission for HF (HR 0.74, 95\% CI 0.60-0.90), but the authors did not assess the quality of evidence and therefore reached different conclusions. The results from our subgroup analyses showed more benefit of BNP-guided therapy in patients $<75$ years old and patients with HFrEF, which is consistent with the analyses reported by Troughton et al. [9] and Brunner La-Rocca et al. [17].

\section{Was the treatment effect a result of decreasing BNP or up-titration of medication?}

The observed benefit in the BNP-guided therapy group could not be attributed to changes in BNP levels during follow-up between groups (Fig. 5). There was no consistent relationship between the relative BNP change from baseline between groups and the hazard ratio for all-cause mortality. Although the smaller RCTs showed a relatively large BNP change between groups and lower hazard ratios, this was not reflected in the larger RCTs that provided most weight in the meta-analysis. The meta-analysis by Troughton et al. [9] showed that BNP levels decreased by $35 \%$ in the BNP-guided therapy group and $32 \%$ in the symptom-guided therapy group. 


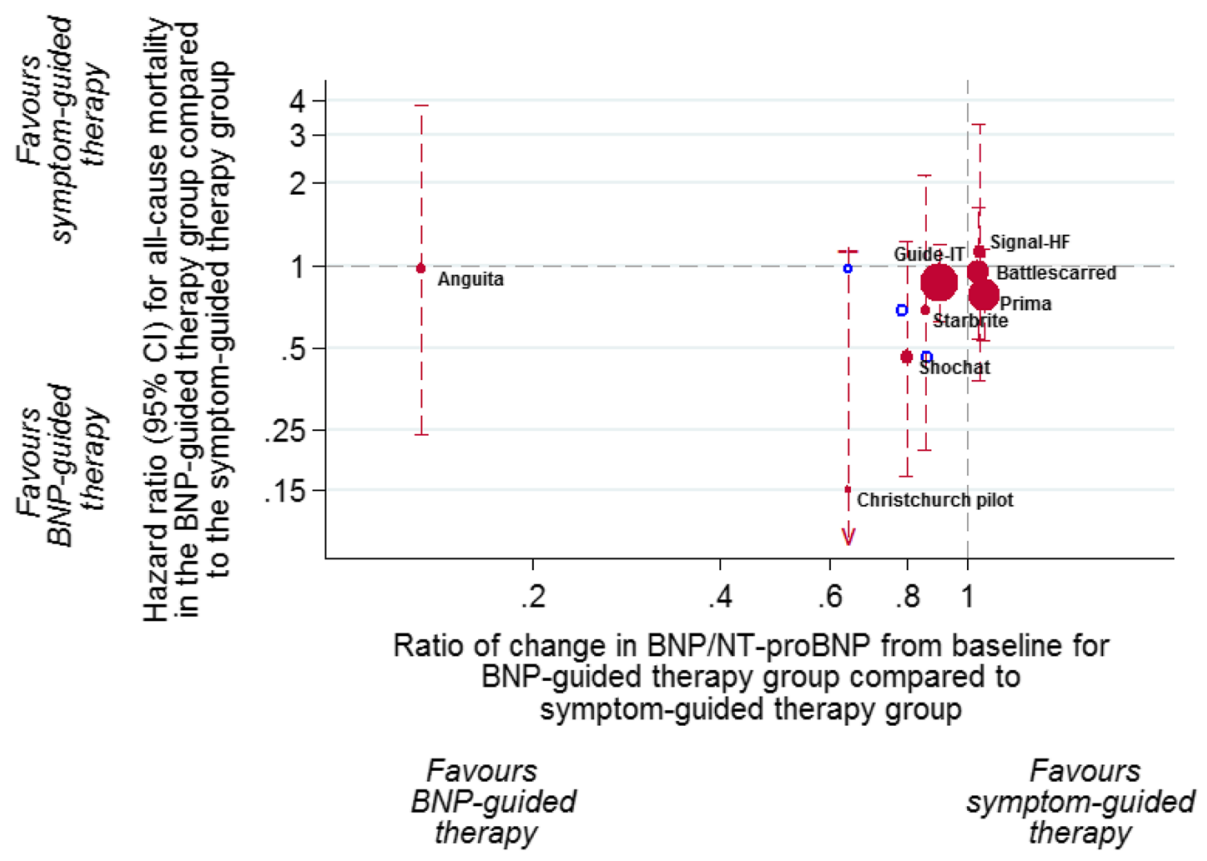

Fig. 6 Relationship between hazard ratios (HR) for all-cause mortality and the ratio of change in BNP/NT-proBNP from baseline between the BNPguided therapy group and symptom-guided therapy group. Filled circles represent the ratio of the change calculated using aggregate data, and open circles represent the ratio of the change calculated using IPD; the change in the position on the $x$-axis shows the differences between the two analyses methods, while the position on the $y$-axis remains the same

Similarly, the Guide-IT RCT showed a 53\% decrease in the BNP-guided therapy group and a $48 \%$ decrease in the symptom-guided therapy group.

Although we could not determine whether and how HF medication doses changed during follow up, the meta-analysis by Troughton et al. [9] showed no differences in medication dose changes between groups, except for a modest increase in doses of angiotensin-converting enzyme inhibitors (ACEi)/angiotensin II receptor blockers (ARB) in the BNP-guided therapy group $(8.4 \%$ increase, 3.4 to 13 , vs. $-1.2 \%$ decrease, -6.1 to 3.7 in the symptom-guided therapy group). While treatment with ACEi and ARB according to guidelines has been shown to reduce the risk of death and hospitalisation in both RCTs and large registries [35-38]; over $89 \%$ of patients in the RCTs were already receiving these medications [9], so it is unclear whether the relatively small dose increases in the BNP-guided therapy group were responsible for the benefit

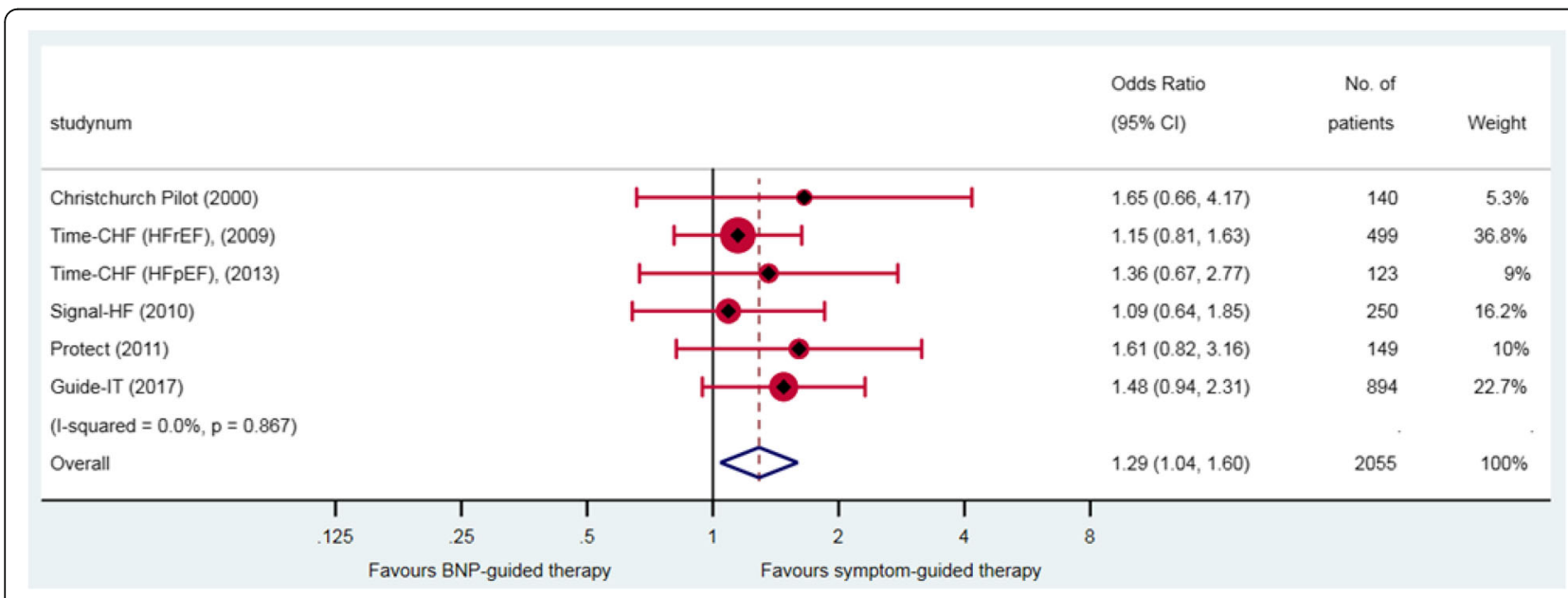

Fig. 7 Total adverse events. Odds ratios (OR) and 95\% confidence intervals (Cl) for five aggregate data studies. Note: weights are from random effect analysis 
observed. Furthermore, the Guide-IT RCT showed modest intensification of $\mathrm{HF}$ medications, including $\mathrm{ACEi}$ and $\mathrm{ARB}$, in both groups.

\section{BNP-lowering vs. BNP-monitoring strategy}

In our meta-analysis, we included all RCTs that used serial BNP measurements to guide HF therapy, regardless of the guiding strategy used. There were several reasons for this. First, we aimed to provide realistic treatment effect estimates given that, in the absence of established guidelines describing how treatment should be guided by BNP, clinicians are likely to use BNP levels to manage their patients in diverse ways (e.g. to check the status quo, to lower BNP as much as possible, or to a target). Second, the two strategies are not fundamentally dissimilar, since both will prompt a patient review with intensification of medications if considered appropriate. Third, RCTs evaluating BNP-lowering were themselves heterogeneous in design, treatment strategies (in both the BNP group and the control group), and BNP target. Finally, we wished to include all studies in order to avoid publication related biases, data availability bias, and reviewer selection bias [39-41]; previous meta-analyses did not publish a priori protocols. These biases can lead to meta-analyses being biased towards more favourable treatment effects [41, 42] and have been highlighted as a potential problem in meta-analyses that use IPD [41]. The exclusion of two studies that did not target a specific BNP level $[27,32]$ did not alter the findings of our meta-analysis.

\section{Strengths and limitations of this study}

Our meta-analysis has several strengths. We systematically identified all RCTs evaluating BNP-guided therapy in HF patients, included all RCTs for which IPD or aggregate data were available, and conducted meta-analyses in accordance with a pre-specified protocol [12] and published guidelines. There was no evidence of publication bias or a small study effect (for all-cause mortality and HF hospitalisation, which had data from more than 10 studies).

The main limitation was our inability to obtain IPD from most of the RCTs included in the meta-analysis by Troughton et al. [9], which constrained our sub-group analyses. Other limitations arose from the design of the RCTs: heterogeneity in how BNP-guided therapy and symptom-guided therapy was administered; restricted eligibility (mainly younger patients with $\mathrm{HFrEF}$ and without co-morbidities), limiting the applicability of the results to the broader HF population; and the potential for bias because most RCTs did not blind clinicians or patients to treatment allocation. This lack of blinding means that co-interventions affecting outcomes could have been initiated by either the doctors or the participants themselves, conditional on their knowledge of the allocation. Also, despite combining results from 14 RCTs, the pooled sample size (up to 3968 patients with HF) was relatively small in comparison with sample sizes in other meta-analyses in this patient population (some of which included over 13,000 patients [43]); therefore, chance may explain some of the apparently significant findings. Finally, data on adverse events were not reported consistently and therefore only five studies contributed data for a meta-analysis.

\section{Implications for clinicians and policy-makers}

Our meta-analysis has shown that BNP-guided treatment in hospital cardiology clinics significantly reduced HF hospitalisation but not all-cause or cardiovascular mortality. However, this conclusion may not be applicable to other health settings and HF patients who were not eligible (older patients with HFpEF). By contrast, across many European countries, cardiologists do not lead the management of patients with HF, and about half of all patients have HFpEF. Patients with HFpEF tend to be older with more comorbidities than their HFrEF counterparts. There are significant gaps and variation in the medical care of HF patients, and there is evidence that not all patients are receiving optimal treatment according to guidelines [44]. It therefore appears more prudent in the first instance to ensure adherence to guidelines for managing HF before recommending BNP-guided therapy.

\section{Conclusion}

The conclusions about the efficacy of BNP-guided therapy are uncertain because the findings are of borderline statistical significance and the overall quality of the evidence varied from low to very low. We could not identify an optimal BNP monitoring strategy and no group of researchers has defined one. Therefore, consensus about an optimal BNP monitoring strategy should urgently be sought, preferably through a formal process involving cardiologists, general practitioners, and patients. It is striking that BNP levels decreased, and HF medications increased in both the BNP-guided therapy and symptom-guided therapy groups in the RCTs; this strongly suggests that HF management outside the RCTs was suboptimal. The reasons why not all patients receive care according to guidelines is unclear; understanding why may require qualitative research with different types of practitioner who care for HF patients.

\section{Additional files}

Additional file 1: Appendix 1. Literature search. (DOCX $18 \mathrm{~kb}$ )

Additional file 2: Appendix 2. Risk of bias. (DOCX 132 kb) 
Additional file 3: Appendix 3. Funnel plots. (DOCX $41 \mathrm{~kb}$ )

Additional file 4: Appendix 4. Subgroup analyses. (DOCX $851 \mathrm{~kb}$ )

\section{Abbreviations}

ACEi: Angiotensin-converting enzyme inhibitors; ARB: Angiotensin II receptor blockers; BNP: B-type natriuretic peptide; Cl: Confidence interval; HF: Heart failure; HFpEF: Heart failure with preserved ejection fraction; HFrEF: Heart failure with reduced ejection fraction; HR: Hazard ratio; IPD: Individual participant data; LV: Left ventricular; LVEF: Left ventricular ejection fraction; NT-proBNP: N-terminal pro-B-type natriuretic peptide; NYHA: New York Heart Association; QoL: Quality of life; RCT: Randomised controlled trial

\section{Acknowledgements}

The study is part of a project funded by a National Institute for Health Research (NIHR) Health Technology Assessment (HTA) programme (HTA 11/ 102/03) and supported by the NIHR Bristol Biomedical Research Unit in Cardiovascular Disease. The views expressed are those of the authors and not necessarily those of the NHS, the NIHR or the Department of Health. We would like to thank Dr. Noreen Hopewell-Kelly, the PPI lead in the NIHR Bristol Biomedical Research Unit, for organising and facilitating the PPI meeting with patients. We would also like to thank Dr. Monica R. Shah for kindly providing IPD for the Starbrite RCT.

\section{Funding}

This study is part of a larger study funded by the UK NIHR Health Technology Assessment (HTA 11/102/03) programme. The views expressed are those of the author(s) and not necessarily those of the NHS, the NIHR, or the Department of Health and Social Care.

\section{Availability of data and materials}

The literature search is based on the published search strategy and can be obtained by contacting the corresponding author

(maria.pufulete@bristol.ac.uk). No additional data are available.

\section{Authors' contributions}

MP lead researcher who established the IPD collaboration, conducted the systematic review, and wrote the manuscript. RM carried out the metaanalyses and drafted some of the results sections of the manuscript. LD screened the abstracts and extracted the data for the systematic review, liaised with IPD collaborators, and drafted some sections of the manuscript. $\mathrm{JH}$ provided methodological advice on the systematic review and metanalysis, and revised the manuscript with respect to intellectual content. CR provided advice on meta-analyses and revised the manuscript with respect to intellectual content. MD advised about secondary care aspects of heart failure management and interpretation of the findings, and revised the manuscript with respect to intellectual content. JM advised about primary care aspects of heart failure management and interpretation of the findings, and revised the manuscript with respect to intellectual content. SP advised about primary care aspects of heart failure management and interpretation of the findings, and revised the manuscript with respect to intellectual content. WH advised with the interpretation of the findings and revised the manuscript with respect to intellectual content.MS advised about the interpretation of the findings and revised the manuscript with respect to intellectual content. MAS advised about the interpretation of the findings and revised the manuscript with respect to intellectual content. PK advised with the interpretation of the findings and revised the manuscript with respect to intellectual content. MKS advised with the interpretation of the findings and revised the manuscript with respect to intellectual content. TM advised about secondary care aspects of heart failure management and interpretation of the findings, and revised the manuscript with respect to intellectual content. AN advised about secondary care aspects of heart failure management and interpretation of the findings, and revised the manuscript with respect to intellectual content. BR is the chief investigator with overall responsibility for the project who provided strategic direction for the systematic review and interpretation of the findings, and revised the manuscript with respect to intellectual content. All authors read and approved the final manuscript.

\section{Ethics approval and consent to participate}

All original trials reported gaining the approval of an appropriate human ethics committee. The current analysis involves a secondary analysis of anonymised data; therefore, it does not require separate ethics committee approval.

\section{Consent for publication}

Not applicable.

\section{Competing interests}

The authors declare that they have no competing interests.

\section{Publisher's Note}

Springer Nature remains neutral with regard to jurisdictional claims in published maps and institutional affiliations.

\section{Author details}

${ }^{1}$ Clinical Trials and Evaluation Unit, School of Clinical Sciences, University of Bristol, Level 7, Bristol Royal Infirmary, Queen's Building, Bristol BS2 8HW, UK. ${ }^{2}$ School of Social and Community Medicine, University of Bristol, Bristol, UK. ${ }^{3}$ Department of Cardiology, Taunton and Somerset NHS Foundation Trust, Taunton, UK. ${ }^{4}$ Herlev and Gentofte University Hospital, Herlev, DK-2730 Copenhagen, Denmark. ${ }^{5}$ Agencia de Investigación de la Sociedad Española de Cardiología, Madrid, Spain. 'Division of Cardiology, Department of Medicine, County Hospital Ryhov, Jönköping, Sweden. ${ }^{7}$ Heart Institute, Hillel Yaffe Medical Center, Hadera, Israel. ${ }^{8}$ Cardiovascular Division, King's College Hospital, King's College London, Denmark Hill, London SE5 9RS, UK. ${ }^{9}$ Department of Cardiology, Bristol Heart Institute, Bristol Royal Infirmary, Bristol BS2 8HW, UK

Received: 9 March 2018 Accepted: 16 July 2018

Published online: 31 July 2018

\section{References}

1. Hollingworth W, Biswas M, Maishman RL, Dayer MJ, McDonagh T, Purdy S, Reeves BC, Rogers CA, Williams R, Pufulete M. The healthcare costs of heart failure during the last five years of life: a retrospective cohort study. Int J Cardiol. 2016;224:132-8.

2. Sharma A, Ezekowitz JA. Similarities and differences in patient characteristics between heart failure registries versus clinical trials. Current heart failure reports. 2013;10(4):373-9.

3. Felker GM, Hasselblad V, Hernandez AF, O'Connor CM. Biomarker-guided therapy in chronic heart failure: a meta-analysis of randomized controlled trials. Am Heart J. 2009;158(3):422-30.

4. Porapakkham P, Porapakkham P, Zimmet H, Billah B, Krum H. B-type natriuretic peptide-guided heart failure therapy: a meta-analysis. Arch Intern Med. 2010;170(6):507-14.

5. Savarese G, Trimarco B, Dellegrottaglie S, Prastaro M, Gambardella F, Rengo G, Leosco D, Perrone-Filardi P. Natriuretic peptide-guided therapy in chronic heart failure: a meta-analysis of 2,686 patients in 12 randomized trials. PLoS One. 2013;8(3):e58287.

6. Li P, Luo Y, Chen YM. B-type natriuretic peptide-guided chronic heart failure therapy: a meta-analysis of 11 randomised controlled trials. Heart Lung Circ. 2013;22(10):852-60.

7. Xin W, Lin Z, Mi S. Does B-type natriuretic peptide-guided therapy improve outcomes in patients with chronic heart failure? A systematic review and meta-analysis of randomized controlled trials. Heart Fail Rev. 2015;20(1):69-80.

8. De Vecchis R, Esposito C, Di Biase G, Ariano C, Giasi A, Cioppa C. B-type natriuretic peptide-guided versus symptom-guided therapy in outpatients with chronic heart failure: a systematic review with meta-analysis. J Cardiovasc Med (Hagerstown). 2014;15(2):122-34.

9. Troughton RW, Frampton CM, Brunner-La Rocca HP, Pfisterer M, Eurlings LW, Erntell H, Persson H, O'Connor CM, Moertl D, Karlstrom P, et al. Effect of B-type natriuretic peptide-guided treatment of chronic heart failure on total mortality and hospitalization: an individual patient meta-analysis. Eur Heart J. 2014;35(23):1559-67.

10. Pufulete M, Maishman R, Dabner L, Mohiuddin S, Hollingworth W, Rogers CA, Higgins J, Dayer M, Macleod J, Purdy S, et al. Effectiveness and costeffectiveness of serum B-type natriuretic peptide testing and monitoring in patients with heart failure in primary and secondary care: an evidence 
synthesis, cohort study and cost-effectiveness model. Health technology assessment (Winchester, England). 2017;21(40):1-150.

11. Felker GM, Anstrom KJ, Adams KF, Ezekowitz JA, Fiuzat M, Houston-Miller N, Januzzi JL Jr, Mark DB, Pina IL, Passmore G, et al. Effect of natriuretic peptide-guided therapy on hospitalization or cardiovascular mortality in high-risk patients with heart failure and reduced ejection fraction: a randomized clinical trial. Jama. 2017;318(8):713-20.

12. Pufulete $M$, Higgins JP, Rogers CA, Dreyer L, Hollingworth W, Dayer M, Nightingale A, McDonagh T, Reeves BC. Protocol for a systematic review and individual participant data meta-analysis of B-type natriuretic peptideguided therapy for heart failure. Syst Rev. 2014;3:41.

13. Higgins JP, Altman DG, Gotzsche PC, Juni P, Moher D, Oxman AD, Savovic J, Schulz KF, Weeks L, Sterne JA. The Cochrane Collaboration's tool for assessing risk of bias in randomised trials. Bmj. 2011;343:d5928.

14. Parmar MK, Torri V, Stewart L. Extracting summary statistics to perform meta-analyses of the published literature for survival endpoints. Stat Med. 1998;17(24):2815-34

15. Higgins JP, Whitehead A, Turner RM, Omar RZ, Thompson SG. Metaanalysis of continuous outcome data from individual patients. Stat Med. 2001;20(15):2219-41.

16. Thompson SG, Higgins JP. Treating individuals 4: can meta-analysis help target interventions at individuals most likely to benefit? Lancet. 2005; 365(9456):341-6

17. Brunner-La Rocca HP, Eurlings L, Richards AM, Januzzi JL, Pfisterer ME, Dahlstrom U, Pinto YM, Karlstrom P, Erntell H, Berger R, et al. Which heart failure patients profit from natriuretic peptide guided therapy? A metaanalysis from individual patient data of randomized trials. Eur J Heart Fail. 2015;17(12):1252-61.

18. Fisher DJ. Two-stage individual participant data meta-analysis and generalized forest plots. Stata J. 2015;15:369-96.

19. Sterne JAC, Harbord RM. Funnel plots in meta-analysis. Stata J. 2004; 4(4):127-41.

20. Anguita M, Esteban F, Castillo JC, Mazuelos F, Lopez-Granados A, Arizon JM, Suarez De Lezo J. Usefulness of brain natriuretic peptide levels, as compared with usual clinical control, for the treatment monitoring of patients with heart failure. Medicina clinica. 2010;135(10):435-40.

21. Berger R, Moertl D, Peter S, Ahmadi R, Huelsmann M, Yamuti S, Wagner B, Pacher R. N-terminal pro-B-type natriuretic peptide-guided, intensive patient management in addition to multidisciplinary care in chronic heart failure a 3-arm, prospective, randomized pilot study. J Am Coll Cardiol. 2010;55(7):645-53.

22. Eurlings LW, van Pol PE, Kok WE, van Wijk S, Lodewijks-van der Bolt C, Ah B, Lok DJ, Crijns HJ, van Kraaij DJ, de Jonge N, et al. Management of chronic heart failure guided by individual N-terminal pro-B-type natriuretic peptide targets: results of the PRIMA (can PRo-brain-natriuretic peptide guided therapy of chronic heart failure IMprove heart fAilure morbidity and mortality?) study. J Am Coll Cardiol. 2010;56(25):2090-100.

23. Jourdain $P$, Jondeau $G$, Funck $F$, Gueffet $P$, Le Helloco A, Donal E, Aupetit JF, Aumont MC, Galinier M, Eicher JC, et al. Plasma brain natriuretic peptideguided therapy to improve outcome in heart failure: the STARS-BNP multicenter study. J Am Coll Cardiol. 2007;49(16):1733-9.

24. Karlstrom P, Alehagen U, Boman K, Dahlstrom U, Group UP-s. Brain natriuretic peptide-guided treatment does not improve morbidity and mortality in extensively treated patients with chronic heart failure: responders to treatment have a significantly better outcome. Eur J Heart Fail. 2011;13(10):1096-103.

25. Persson H, Erntell H, Eriksson B, Johansson G, Swedberg K, Dahlstrom U. Improved pharmacological therapy of chronic heart failure in primary care: a randomized study of NT-proBNP guided Management of Heart Failure--SIGNAL-HF (Swedish intervention study--guidelines and NTproBNP AnaLysis in Heart Failure). Eur J Heart Fail. 2010;12(12):1300-8.

26. Pfisterer $M$, Buser $P$, Rickli $H$, Gutmann $M$, Erne $P$, Rickenbacher $P$, Vuillomenet A, Jeker U, Dubach P, Beer H, et al. BNP-guided vs symptomguided heart failure therapy: the Trial of Intensified vs Standard Medical Therapy in Elderly Patients With Congestive Heart Failure (TIME-CHF) randomized trial. Jama. 2009;301(4):383-92.

27. Schou M, Gustafsson F, Videbaek L, Andersen H, Toft J, Nyvad O, Ryde H, Fog L, Jensen JC, Nielsen OW, et al. Adding serial N-terminal pro brain natriuretic peptide measurements to optimal clinical management in outpatients with systolic heart failure: a multicentre randomized clinical trial (NorthStar monitoring study). Eur J Heart Fail. 2013;15(7):818-27.
28. Lainchbury JG, Troughton RW, Strangman KM, Frampton CM, Pilbrow A, Yandle TG, Hamid AK, Nicholls MG, Richards AM. N-terminal pro-B-type natriuretic peptide-guided treatment for chronic heart failure: results from the BATTLESCARRED (NT-proBNP-assisted treatment to lessen serial cardiac readmissions and death) trial. J Am Coll Cardiol. 2009;55(1):53-60.

29. Troughton RW, Frampton CM, Yandle TG, Espiner EA, Nicholls MG, Richards AM. Treatment of heart failure guided by plasma aminoterminal brain natriuretic peptide (N-BNP) concentrations. Lancet. 2000;355(9210):1126-30.

30. Januzzi JL Jr, Rehman SU, Mohammed AA, Bhardwaj A, Barajas L, Barajas J, Kim HN, Baggish AL, Weiner RB, Chen-Tournoux A, et al. Use of aminoterminal pro-B-type natriuretic peptide to guide outpatient therapy of patients with chronic left ventricular systolic dysfunction. J Am Coll Cardiol. 2011:58(18):1881-9.

31. Shah MR, Califf RM, Nohria A, Bhapkar M, Bowers M, Mancini DM, Fiuzat M, Stevenson LW, O'Connor CM. The STARBRITE trial: a randomized, pilot study of B-type natriuretic peptide-guided therapy in patients with advanced heart failure. J Card Fail. 2011;17(8):613-21.

32. Shochat M, Shotan A, Dahan I, Shochat I, Levy Y, Asif A, Kazatsker M, Blondheim D, Meisel S. NT-proBNP-Guided Preemptive Treatment of Outpatients with Chronic Heart Failure Followed in a Out Hospital Clinic. J Card Fail. 2011:17(8):S56.

33. Maeder MT, Rickenbacher P, Rickli $H$, Abbuhl H, Gutmann M, Erne P, Vuilliomenet A, Peter M, Pfisterer M, Brunner-La Rocca HP, et al. N-terminal pro brain natriuretic peptide-guided management in patients with heart failure and preserved ejection fraction: findings from the trial of intensified versus standard medical therapy in elderly patients with congestive heart failure (TIME-CHF). Eur J Heart Fail. 2013;15(10):1148-56.

34. Karlstrom P, Johansson P, Dahlstrom U, Boman K, Alehagen U. Can BNP-guided therapy improve health-related quality of life, and do responders to BNP-guided heart failure treatment have improved health-related quality of life? Results from the UPSTEP study. BMC cardiovascular disorders. 2016;16:39.

35. The CONSENSUS Trial Study Group. Effects of enalapril on mortality in severe congestive heart failure. Results of the Cooperative North Scandinavian Enalapril Survival Study (CONSENSUS). N Engl J Med. 1987; 316(23):1429-35.

36. The SOLVD Investigators. Effect of enalapril on survival in patients with reduced left ventricular ejection fractions and congestive heart failure. $\mathrm{N}$ Engl J Med. 1991;325(5):293-302.

37. Cohn JN, Tognoni G. A randomized trial of the angiotensin-receptor blocker valsartan in chronic heart failure. N Engl J Med. 2001;345(23):1667-75.

38. Neubauer $S$, Schilling T, Zeidler J, Lange A, Engel S, Linder R, Verheyen F, von der Schulenburg JG, Haverich A. Impact of guideline adherence on mortality in treatment of left heart failure. Herz. 2016;41(7):614-24.

39. Cochrane Individual Participant Data (IPD) Meta-analysis Methods Group. http://ipdmamg.cochrane.org/resources. Accessed 26 July 2018.

40. Higgins JPT, Thomas J (editors). Cochrane Handbook for Systematic Reviews of Interventions Version 5.2 [updated June 2017, online version]. The Cochrane collaboration. Available from https://training.cochrane.org/ handbook.

41. Ahmed I, Sutton AJ, Riley RD. Assessment of publication bias, selection bias, and unavailable data in meta-analyses using individual participant data: a database survey. Bmj. 2012;344:d7762.

42. Burdett S, Stewart LA, Tierney JF. Publication bias and meta-analyses: a practical example. Int J Technol Assess Health Care. 2003;19(1):129-34.

43. Kotecha D, Manzano L, Krum H, Rosano G, Holmes J, Altman DG, Collins PD, Packer M, Wikstrand J, Coats AJ, et al. Effect of age and sex on efficacy and tolerability of beta blockers in patients with heart failure with reduced ejection fraction: individual patient data meta-analysis. Bmj. 2016;353:i1855.

44. Healthcare Commission. Pushing the boundaries: improving services for people with heart failure. London: Healthcare Commission.

45. Karavidas A, Konstantinou K, Nikolaou M, Matzaraki V, Papoutsidakis N, Pyrgakis $V$, Parissis J. Guiding decongestion treatment in chronic heart failure patients. Clinical assessment or serial laboratory evaluation? Eur Heart J. 2013;34(1):647.

46. Ak T, Gaze D, Ajs C, Dumitrascu D, Spinarova L, Collinson P, Roughton M, Flather MD, Investigators S. Effects of nebivolol on biomarkers in elderly patients with heart failure. Int J Cardiol. 2014;175:253-60.

47. Krupika J, Janota T, Hradec J. Optimalization of heart failure therapy guided by plasma BNP concentrations. Eur Heart J. 2010;31(1):859-60. 
48. Koshkina D, Skvortsov A, Narusov O, Protasov V, Nasonova S, Masenko V Tereshchenko S. NT-proBNP-guided treatment of high risk heart failure patients after acute decompensation. Eur Heart J. 2015; Conference: European Society of Cardiology, ESC Congress 2015 London United Kingdom. Conference Start: 20150829 Conference End: 20150902. Conference Publication:153-154.

49. Ueda K, Hirahashi J, Seki G, Tanaka M, Kushida N, Takeshima Y, Nishikawa Y, Fujita T, Nangaku M. Successful Treatment of Acute Kidney Injury in Patients with Idiopathic Nephrotic Syndrome Using Human Atrial Natriuretic Peptide. Internal medicine (Tokyo, Japan). 2014;53:865-9.

Ready to submit your research? Choose BMC and benefit from:

- fast, convenient online submission

- thorough peer review by experienced researchers in your field

- rapid publication on acceptance

- support for research data, including large and complex data types

- gold Open Access which fosters wider collaboration and increased citations

- maximum visibility for your research: over $100 \mathrm{M}$ website views per year

At $\mathrm{BMC}$, research is always in progress.

Learn more biomedcentral.com/submissions 